\title{
Nosocomial transmission of bloodborne viruses from infected health care workers to patients
}

\author{
B Lynn Johnston $\mathrm{MD}^{1}$, John M Conly $\mathrm{MD}^{2}$
}

$\mathrm{T}$ he risks to health care workers (HCWs) of occupationallyacquired infection with hepatitis B virus (HBV), human immunodeficiency virus (HIV) and, to a lesser extent, hepatitis $\mathrm{C}$ virus (HCV) have been reasonably well quantified (1). Evidence from the HIV and HBV experience suggests that the risk of infection is increased where the level of viremia is high, as manifested by high HIV viral load or the presence of hepatitis B e antigen ( $\mathrm{HbeAg}$ ) (1). It has also been recognized that patients may acquire one of these viruses following significant exposure to the blood of an infected HCW (2-4). While the magnitude of this risk to patients is considerably less than that to HCWs, the 1990 report by the Centers for Disease Control and Prevention (CDC) that a Florida dentist had transmitted HIV to patients in the course of dental care triggered widespread public concern about the risk of infection from HCWs. In 1991 CDC published recommendations for preventing HIV and HBV transmission to patients, which included the recommendation that HCWs who are infected with HIV or HBV (and HbeAg positive, a marker of higher infectivity) should not perform exposure-prone procedures unless they have sought counsel from an expert review panel (5). In 1998, Health Canada published guidelines for the management of HCWs infected with HBV, HCV, and/or HIV (6). Both these documents generated controversy at the time of their publication. Since that time, however, several provincial regulatory bodies have formed committees to advise physicians infected with these bloodborne pathogens (BBPs) regarding their practice. This article reviews what we know about the transmission of HBV, HCV and HIV from infected HCWs to patients in medical and dental settings.

\section{HEPATITIS B}

Several studies have examined the prevalence of HBV markers in HCWs. A 1985 study in Italy found that prevaccination immunological markers of current or past HBV infection were found in $23.3 \%$ of HCW sested, with $1.8 \%$ being HBV surface antigen positive (7). The prevalence of serological markers for HBV in Chicago HCWs in 1983 was $15.2 \%$, with 1\% HBV surface antigen positive (8). These results are similar to a previous study conducted between June 1977 and October 1978 of $624 \mathrm{HCW}$ in Boston (9). A more recent prevaccination study of HCWs in San Francisco (1984 to 1992) found that 21.7\% had markers of HBV infection (10). While it is expected that the prevalence of HBV in HCWs will go down with community and occupational HBV vaccination programs, in the immediate future it is anticipated that there will continue to be chronically infected HCWs who have come from endemic areas or previously had other non-occupational exposures.

The first reported transmission of HBV from HCW to patient was in 1972 (11). In that study, cases of icteric hepatitis in 11 patients were linked to a nurse with HBV, but the mode of transmission was not determined (11). Since that time, there have been a number of isolated transmissions and outbreaks of HBV related to patient exposures to infected HCWs (Table 1). The methodology used in these studies has differed considerably and many of the early studies are flawed by several factors: the vast majority were retrospective; case finding was confined to symptomatic patients; only a minority of exposed patients had serological testing; and it was often impossible to distinguish infection related to $\mathrm{HCW}$ exposure from that due to other exposures. While more recent studies have been rigorous in their follow-up of potentially exposed patients, there still remains the difficulty of distinguishing the source of hepatitis B infection in those who no longer have detectable viremia for molecular typing. To date, therefore, it has not been possible to precisely quantify the risk of transmission to patients from a significant exposure to an infected HCW. However, it is apparent that a number of infected HCWs have been associated with nosocomial transmissions to patients since 1972 (2,11-34).

In an effort to develop a better understanding of the risk of nosocomial HBV transmission, investigators in the 1970s and 1980s did serological testing on patients cared for by HBV carrier HCWs who had not been associated with the transmission of clinical infection (35-37). None of these studies demonstrated transmission of HBV from infected HCWs to patients. However, these studies had limitations that could have affected their results. The first study involved no surgical personnel (35). The second study had complete serological evaluation on only 28 of 49 patients operated on by an orthopedic resident with acute hepatitis B (36). In the third study, of 213 patients exposed to six chronic carrier physicians (two surgeons), it could not be determined how many were exposed to the surgeon who was $\mathrm{HBeAg}$ positive (37).

Some important observations can be made by examining the studies that have looked at transmission of HBV from infected HCWs to patients. The limited data suggest that HBV-infected HCWs who are not involved in invasive procedures do not transmit infection $(35,37)$ unless there are breaches of infection control (32). It would appear that not

${ }^{1}$ Departments of Pathology and Laboratory Medicine, Medicine, and Microbiology and Infectious Diseases, University of Calgary, Calgary, Alberta; ${ }^{2}$ Queen Elizabeth II Health Sciences Centre and Dalhousie University, Halifax, Nova Scotia

Correspondence: Dr John Conly, Departments of Pathology and Laboratory Medicine, Medicine, and Microbiology and Infectious Diseases, Room 930, 9th Floor, North Tower, 1403 29th Street Northwest, Calgary, Alberta T2N 2T9. Telephone 403-944-8222, fax 403-944-1095, e-mail jconly@ucalgary.ca and Dr Lynn Johnston, Department of Medicine, Room 5014 ACC, Queen Elizabeth II Health Sciences Centre, 1278

Tower Road, Halifax, Nova Scotia B3H 2Y9. Telephone 902-473-5553, fax 902-473-7394, e-mail ljohnsto@dal.ca 
TABLE 1

Physician and dentist/oral surgeon-to-patient transmissions of hepatitis B

\begin{tabular}{|c|c|c|c|c|c|c|c|}
\hline Country & Year & Specialty & eAg & Cases & Survey & Disposition & Outcome \\
\hline US (12) & 1972 & Dentist & ND & 13 & no & Stopped practice & - \\
\hline US (13) & 1974 & Oral surgeon & ND & 55 & no & Returned to practice with gloves & No further transmissions \\
\hline US (14) & 1975 & Oral surgeon & ND & 43 & no & Returned to practice with gloves & 1 transmission $->$ restricted \\
\hline US (15) & 1978 & Dentist & + & 6 & yes & Returned to practice with gloves & No further transmissions \\
\hline US (16) & 1979 & Oral surgeon & + & 12 & yes & Stopped practice & - \\
\hline US (17) & 1980 & Oral surgeon & ND & 55 & yes & Returned to practice with gloves & No further transmissions \\
\hline US (18) & 1980 & Dentist & ND & 4 & no & Returned to practice with gloves & No further transmissions \\
\hline US (19) & 1984 & Dentist & + & 24 & yes & Stopped practice & - \\
\hline England (20) & 1978 & Gynecology & + & 8 & no & Practice restricted & - \\
\hline US (21) & 1979 & Gynecology & + & 4 & no & $\begin{array}{l}\text { Returned to practice double gloving } \\
\text { and technique modification }\end{array}$ & No further transmissions \\
\hline England (22) & $1976-79$ & Obstet/Gyn & + & 9 & no & Practice restricted & - \\
\hline US (23) & 1984 & Obstet/Gyn & + & 6 & yes & Returned with technique modification & 1 transmission $\rightarrow>$ restricted \\
\hline England (24) & 1987 & Obstet/Gyn & + & 22 & yes & Stopped practice & - \\
\hline England (25) & 1993 & Obstet & - & 3 & yes & Practice restricted & - \\
\hline England (25) & 1994 & Gynecology & - & 1 & yes & Practice restricted & - \\
\hline Norway (26) & 1978 & CV Surgery & + & 5 & yes & Acute HBV resolved; returned to practice & - \\
\hline Nether-lands (27) & 1979 & CV Surgery & ND & 3 & no & Acute HBV resolved; returned to practice & - \\
\hline England (28) & 1987 & CV Surgery & + & 17 & yes & Practice restricted & - \\
\hline England (29) & 1990 & CV Surgery & + & 5 & yes & Not indicated & - \\
\hline England (30) & $1992-93$ & CV Surgery & + & 20 & yes & Stopped practice & - \\
\hline US (2) & 1992 & CV Surgery & + & 19 & yes & Stopped practice & - \\
\hline Scotland (31) & 1999 & CV Surgery & - & 2 & yes & Practice restricted & - \\
\hline Switzer-land (32) & 1973-77 & Gen Practice & + & 36 & no & Worked with practice modifications & $\begin{array}{l}\text { Died following } 2 \text { more } \\
\text { transmissions }\end{array}$ \\
\hline England (25) & 1988 & Gen Surgery & - & 1 & no & Practice restricted & - \\
\hline England (25) & 1995 & Gen Surgery & - & 1 & yes & Practice restricted & - \\
\hline Canada (33) & 1991 & Orthopedic & + & 4 & yes & Practice restricted & - \\
\hline England (34) & 1996 & Orthopedic & - & 1 & yes & Practice restricted & - \\
\hline
\end{tabular}

CV Cardiovascular; eAg Hepatitis B e Antigen; Gen General; Gyn Gynecology; ND Not done; Obstet Obstetrics

all HBV- infected HCWs who perform invasive procedures transmit infection to patients (36). However, HBV-infected HCWs have been associated with nosocomial transmissions $(2,12-34)$. Physicians associated with transmissions have been at all levels of experience including trainees, clinical assistants and senior surgeons. Technical expertise or competence has not usually been identified as a contributing factor in the transmissions.

In the literature on nosocomial HBV transmissions, a few specialties appear to be over-represented, including dentistry and oral surgery, obstetrics and gynecology, and cardiothoracic/cardiovascular surgery. It has been suggested that these are specialties where surgery involves one or more of the following: operating in a confined and/or poorly visualized field, palpation of needles or other sharp objects, or frequent exposure to sharp objects, all of which increase the potential for the HCW's blood to come into contact with the patient's blood or open tissues. This has led to the terminology "exposureprone procedures," first coined by the CDC in 1991 (5). Characteristics of exposure-prone procedures include digital palpation of a needle tip in a body cavity or the simultaneous presence of the HCW's fingers and a needle or other sharp instrument or object in a poorly visualized or highly confined anatomical site (5). There have been no reported HBV transmissions related to dental or oral surgery since the implemen- tation of universal precautions in 1987. Additionally, four of the dentists/oral surgeons associated with outbreaks returned to practice with their practices modified to include the routine use of gloves $(13,15,17,18)$. These observations highlight the importance and effectiveness of education of the HCWs and the use of gloves in preventing the transmission of BBPs in the dental setting.

Until 1997, all HCWs associated with HBV transmissions who were tested were $\mathrm{HbeAg}$ positive, which is associated with higher levels of circulating virus and greater infectivity $(2,15,16,19-24,26,28-30,32,33)$. This was identified as a marker for HCWs who should refrain from performing exposure-prone procedures $(5,25)$. Since that time, there have been several reported transmissions involving physicians who were $\mathrm{HBeAg}$ negative, documenting that they may also transmit infection $(25,31,34)$. Detailed investigations of the surgeons in these transmissions revealed that all carried a precore HBV mutant $(25,31,34)$. This mutation, located in the genome just before the gene that codes for the core protein, prevents expression of the e antigen (34). The mutation does not interfere with the replication of infectious virus and some individuals with this precore mutant will have high levels of circulating HBV DNA (25). It is not known what proportion of $\mathrm{HBeAg}$-negative carriers have the precore mutant, nor whether this mutation is more or less likely to be associated with nosocomial transmissions (25). 
The ability to accurately measure the serum HBV DNA level might allow a more precise determination of the degree of infectivity of carriers. In-house assays of blood from five HBeAgnegative surgeons found the lowest level of HBV DNA to cause infection was $2.5 \times 10^{5}$ copies per $\mathrm{ml}(25,34)$. Based on this, it has been suggested that the cutoff HBV DNA level below which an HBeAg-negative carrier would become non-infectious would probably be around $10^{4} \mathrm{HBV}$ DNA copies per ml (38). It should be noted that the performance characteristics of some commercial assays may not detect this level of viremia (38).

More recent look-back surveys of patients exposed to infected surgeons have provided an estimate of transmission risk ranging from $0.5 \%$ to $13 \%(2,25,31,34)$. Risk factors for infection have not been identified, but can be speculated to include the host's health, immune system and vaccine status, as well as the route of infection, volume of inoculum, HBV DNA level, and strain pathogenicity (38).

\section{HUMAN IMMUNODEFICIENCY VIRUS}

In four serosurveys $(7,10,39,40)$, the overall prevalence of HIV infection among $\mathrm{HCW}$ s ranged from $0.4 \%$ to $0.7 \%$ and was similar for medical and dental workers. Given the smaller risk for transmission of HIV compared to HBV, it is not surprising that HIV prevalence is substantially lower than HBV in HCWs. Similarly, it would be expected that the rate of transmission from HIV-infected HCWs to patients would be extremely low. In 1990, the CDC reported that a Florida dentist with AIDS may have infected one of his patients in the course of dental surgery (3). The public reaction to this was unprecedented and focussed attention on the issue of HCWs infected with BBPs. In the end, the CDC, through its epidemiological and molecular investigations, concluded that the Florida dentist had infected six of his patients in the course of their dental care $(41,42)$. The precise mode of HIV transmission to these patients could not be identified and likely never will be.

The Florida dental case was particularly a mystery given the number of prior and subsequent look-back investigations that failed to identify HIV transmission from infected HCWs to patients (43-47). In 1995, the CDC published information on investigations of $64 \mathrm{HIV}$-infected HCWs that had been reported to them (48). HIV test results were available for 22,171 patients of 51 of the $64 \mathrm{HCW}$. Thirty-seven of these 51 workers had no seropositive patients among the 13,063 tested. While there were 113 seropositive patients for the remaining 14 HCWs, epidemiological and laboratory follow-up failed to etiologically link HCW and patient.

In 1999, a study from France (49) provided evidence that an HIV-infected orthopedic surgeon may have transmitted HIV to one of his patients during surgery. The patient, a 67-year-old woman with no other HIV risks, had undergone a difficult replacement of a total hip prosthesis with bone graft in 1992 and removal of the prosthesis in 1993. She tested HIV negative in 1992 and positive in 1994. The surgeon's and patient's viruses, although similar, displayed a $15.2 \%$ difference, which was attributed to mutational changes between the time of infection and testing. The surgeon reported both frequent opportunities for blood exposures (as frequently as once a week) and actual blood exposures. He often tightened suture wires with his fingers, sometimes tied sutures with the needle still attached, sometimes directed the needle with his fingers, and used digital palpation of the needle tip during the placement of bone pins. Since 1983, he routinely double-gloved for operations and changed gloves after needlestick injuries or procedures longer than $1.5 \mathrm{~h}$. While this report is evidence of the potential for HIV transmission from an infected HCW to his or her patient under certain situations, it must be viewed in the context of an overall extremely low risk and one that should be preventable by safer techniques for handling instruments, manipulating sutures and closing wounds (50).

\section{HEPATITIS C}

Various studies have placed the prevalence of $\mathrm{HCV}$ in $\mathrm{HCW}$ at between $1.4 \%$ and $2.0 \%$, which is comparable to the rate in the general population $(7,10,51-53)$. Within the disciplines, however, some groups have a higher prevalence for HCV, suggesting that there are some occupations that carry a higher risk than others. In two studies in the United States $(52,53)$ there was a higher rate of $\mathrm{HCV}$ in oral surgeons $(2.0 \%$ to $9.3 \%)$ than other dentists $(0.7 \%$ to $0.97 \%)$.

The epidemiology of HCV transmission from infected $\mathrm{HCW}$ to patient is very similar to that of HBV. During a prospective study of the efficacy of HCV serological assays in preventing transfusion-related $\mathrm{HCV}$ infection, investigators identified two patients who developed acute hepatitis $\mathrm{C}$ in relation to open-heart surgery (4). It was subsequently determined that these two, and at least three other patients, probably acquired their infection from a cardiac surgeon with hepatitis $\mathrm{C}$. The surgeon reported experiencing about 20 percutaneous injuries per 100 procedures, most often in the course of tying the wires during closure of the sternum. He also reported two percutaneous injuries with sharp objects and needles per 100 procedures, for which he would remove the instrument from the field and change gloves. Since that time, there has been another report of transmission of HCV to a patient after cardiothoracic surgery (54) and two reports of transmission to patients during gynecologic surgery $(55,56)$. In two of these studies $(54,56)$, all patients exposed to the infected surgeons through exposure-prone procedures were requested to undergo serological testing. No further transmissions were identified, and the overall infection rate was $0.36 \%$ for cardiothoracic surgery (54) and $0.04 \%$ for gynecologic surgery (56). Similar to the situation with occupational risk, nosocomial transmissions through exposure to an infected HCW are substantially lower than with HBV.

In addition to these cases linked to exposure-prone procedures performed by an infected surgeon, there is one report of HCV transmission from an anesthesiology assistant to five patients (57). Investigation of this outbreak revealed that the infected HCW usually did not wear gloves during procedures such as placement of arterial and venous catheters and intubation, and had a weeping, uncovered wound on one of his fingers. Other infections-control breaches among staff were identified, including needle recapping, inconsistent glove use and frequent use of multidose vials. These outbreaks highlight the importance of basic infection control in preventing the nosocomial transmission of BBPs.

\section{GUIDELINES FOR THE PREVENTION OF BLOODBORNE PATHOGEN TRANSMISSION FROM HEALTH CARE WORKER TO PATIENT}

In 1991, the CDC published recommendations for preventing the transmission of HIV and HBV to patients during exposureprone invasive procedures (5). They defined exposure-prone procedures as including digital palpation of a needle tip in a 
body cavity or the simultaneous presence of the HCW's fingers and a needle or other sharp instrument or object in a poorly visualized or highly confined anatomical site and recommended that HCWs infected with HIV or HBV (and HBeAg positive) should not perform such procedures unless they sought counsel from an expert review panel. They also stipulated that infected HCWs who continued to perform exposure-prone procedures notify prospective patients. Mandatory testing of $\mathrm{HCW}$ for BBPs was not recommended. No recommendations to restrict professional activity of $\mathrm{HCV}$-infected $\mathrm{HCW}$ s currently exist in the United States (58).

In the United Kingdom, HCWs who are HIV, HCV, and HBV (and HbeAg positive) are not allowed to participate in exposure-prone procedures (59-61). HBV carriers who are HbeAg negative undergo quantitative viral load measurement. If the level is less than 103 copies per $\mathrm{ml}$, they may continue to perform exposure-prone procedures provided they are not associated with a nosocomial transmission (59).

Health Canada published recommendations for HIV- and HBV-infected HCWs in 1992, updating them to include HCV in 1995 and 1996 (6). Any HCW with an infectious disease that could put a patient at risk was encouraged to seek medical evaluation by his or her primary care physician, who in turn was to seek advice on risk for transmission through a consultation mechanism, which was not clearly defined.

To further clarify the management of HCWs infected with a BBP, updated recommendations were published in 1998 following a consensus conference held in November 1996 (6). Exposure-prone procedures were expanded to include repair of major traumatic injuries or major cutting or removal of oral or perioral tissue, including tooth structures. The recommendations covered a number of areas, including the importance of basic infection-control practices in preventing the transmission of BBPs, preventing blood exposures in the health care setting, immunizing and screening of HCWs, and risk management (eg, trace-back and look-back activities) after an infected $\mathrm{HCW}$ has practice modifications imposed. There were more explicit guidelines about referral to an expert panel and the composition of such panels. The panel's mandate would be to assess the transmission risk to patients posed by the infected HCW during exposure-prone procedures and make recommendations on the HCW's practice (6). Mandatory testing was not recommended. Rather, it remained an ethical obligation of HCWs performing exposure-prone procedures to know their serological status and self-report to the profession's regulatory body.

The recommendations made in the 1998 Health Canada report were not supported by the Canadian medical and cental associations (6). Their major concerns appear to relate to mandatory immunization and postimmunization serological testing of HCWs who perform exposure-prone procedures, and HCW loss of privacy and autonomy. However, several provincial physician regulatory bodies have established expert panels to provide guidance to infected HCWs. Continued discussion at the provincial level on how best to minimize the risk of transmission of BBPs from infected HCW to patient is anticipated. While the data are somewhat limited, there is a body of literature to guide expert panels in their deliberations. Unfortunately, there remains no consistent and readily accessible opportunity for retraining the HCW whose practice is limited because of infection with a BBP. While certain disability insurance plans will provide coverage for non-disabled physi- cians whose practices are limited because of infection with a BBP, their practices have to be restricted by regulations approved by an appropriate governmental authority, hospital board, or licensing authority for them to access their benefits. Work needs to be done on facilitating physicians' ethical obligations to report infection with a BBP if they perform exposure-prone procedures.

\section{REFERENCES}

1. Sepkowitz KA. Occupationally acquired infections in health care workers. Part II. Ann Intern Med 1996;125:917-28.

2. Harpaz R, Von Seidlein L, Averhoff FM, et al. Transmission of hepatitis $B$ virus to multiple patients from a surgeon without evidence of inadequate infection control. N Engl J Med 1996;334: 549-54.

3. CDC. Possible transmission of human immunodeficiency virus to a patient during an invasive dental procedure. MMWR 1990;39:489-93.

4. Esteban JI, Gómez J, Martell M, et al. Transmission of hepatitis C by a cardiac surgeon. N Engl J Med 1996;334:555-60.

5. CDC. Recommendations for preventing transmission of human immunodeficiency and hepatitis B virus to patients during exposure-prone invasive procedures. MMWR 1991;40(RR-8):1-9.

6. Health Canada. Proceedings of the consensus conference on infected health care worker risk for transmission of bloodborne pathogens. Can Commun Dis Rep 1998;24(Suppl 4):1-22.

7. Petrosillo N, Puro V, Ippolito G, et al. Hepatitis B, hepatitis C virus and human immunodeficiency virus infection in health care workers: A multiple regression analysis of risk factors. J Hosp Infect 1995;30:273-81.

8. Kessler HA, Harris AA, Payne JA, Hudson E, Potkin B, Levin S. Antibodies to hepatitis B surface antigen as the sole marker in hospital personnel. Ann Intern Med 1985;103:21-6.

9. Dienstag JL, Ryan DM. Occupational exposure to hepatitis B virus in hospital personnel: Infection or immunization? Am J Epidemiol 1982:115:26-39.

10. Gerberding JL. Incidence and prevalence of human immunodeficiency virus, hepatitis $B$ virus, hepatitis $C$ virus, and cytomegalovirus among health care personnel at risk for blood exposure: Final report of a longitudinal study. J Infect Dis 1994:170:1410-7.

11. Garibaldi RA, Rasmussen CM, Holmes AW, Gregg MB. Hospitalacquired serum hepatitis. Report of an outbreak. JAMA 1972;219:1577-80.

12. Levin ML, Maddrey WC, Wands JR, Mendeloff AI. Hepatitis B transmission by dentists. JAMA 1974;228:1139-40.

13. Rimland D, Parkin WE, Miller GB, Schrack WD. Hepatitis B outbreak traced to an oral surgeon. N Engl J Med 1977;296:953-8.

14. Goodwin D, Fannin SL, McCracken BB. An oral-surgeon related hepatitis B outbreak. Calif Morbid 1976;No 14.

14. Hadler SC, Sorley DL, Acree KH, et al. An outbreak of hepatitis B in a dental practice. Ann Intern Med 1981;95:133-8.

16. Reingold AL, Kane MA, Murphy BL, Checko P, Francis DP, Maynard JE. Transmission of hepatitis B by an oral surgeon. J Infect Dis 1982;145:262-8.

17. Goodman RA, Ahtone JL, Finton RJ. Hepatitis B transmission from dental personnel to patients: Unfinished business. Ann Intern Med 1982;96:119.

18. Ahtone J, Goodman RA. Hepatitis B and dental personnel: Transmission to patients and prevention issues. JADA 1983;106:219-22.

19. Shaw FE, Barrett CL, Hamm R. Lethal outbreak of hepatitis B in a dental practice. JAMA 1986;255:3260-4.

20. PHLS Collaborative Study Report. Acute hepatitis B associated with gynaecological surgery. Lancet 1980;i:1-6.

21. Carl M, Blakey DL, Francis DP, Maynard JE. Interruption of hepatitis B transmission by modification of a gynaecologist's surgical technique. Lancet 1982;i:731-3.

22. District Control of Infection Officer. Acute hepatitis B following gynaecological surgery. J Hosp Infect 1987;9:34-8.

23. Lettau LA, Smith JD, Williams D, et al. Transmission of hepatitis B with resultant restriction of surgical practice. JAMA 1986;255:934-7.

24. Welch J, Webster M, Tilzey AJ, Noah ND, Banatvala JE. Hepatitis B infections after gynaecological surgery. Lancet 1989;i:205-7. 
25. The Incident Investigation Team and others. Transmission of hepatitis B to patients from four infected surgeons without hepatits B e antigen. N Engl J Med 1997;336:178-84.

26. Hærem JW, Siebke J-C, Ulstrup J, Geiran O, Helle I. HbSAg transmission from a cardiac surgeon incubating hepatitis B resulting in chronic antigenemia in four patients. Acta Med Scand 1981;210:389-92.

27. Coutinho RA, Albrecht-van Lent P, Stoutjesdijk L, et al. Hepatitis B from doctors. Lancet 1982;i:345-5.

27. Prentice MB, Flower AJE, Morgan GM, et al. Infection with hepatitis B virus after open heart surgery. BMJ 1992;304:761-4.

29. Heptonstall J. Outbreaks of hepatitis B virus infection associated with infected surgical staff. Commun Dis Rep CDR Rev 1991;1:R81-5

30. Incident Control Team and others. Lessons from two linked clusters of acute hepatitis B in cardiothoracic surgery patients. Commun Dis Rep CDR Rev 1996;9:R119-25.

31. Molyneaux P, Reid TMS, Collacott I, McIntyre PG, Dillon JF, Laing RBS. Acute hepatitis B in two patients transmitted from an e antigen negative cardiothoracic surgeon. Commun Dis Public Health 2000;3:250-2.

32. Grob PJ, Bischof B, Naeff F. Cluster of hepatitis B transmitted by a physician. Lancet 1981;ii:1218-20.

33. Johnston BL, Langille DB, LeBlanc JC, et al. Transmission of hepatitis B related to orthopedic surgery. Infect Control Hosp Epidemiol 1994;15:352.

34. Sundkvist T, Hamilton GR, Rimmer D, Evans BG, Teo CG. Fatal outcome of transmission of hepatitis $\mathrm{B}$ from an e antigen negative surgeon. Commun Dis Public Health 1998;1:48-50.

35. Alter HJ, Chalmers TC, Freeman BM, et al. Health-care workers positive for hepatitis B surface antigen. Are their contacts at risk? N Engl J Med 1975;292:454-7.

36. Meyers JD, Stamm WE, Kerr M, Counts GW. Lack of transmission of hepatitis B after surgical exposure. JAMA 1978;240:1725-7.

37. LaBreque DR, Muhs JM, Lutwick LI, Woolson RF, Hierholzer WR. The risk of hepatitis $B$ transmission from health care workers to patients in a hospital setting - A prospective study. Hepatology 1986;6:205-8.

38. Ballard AL, Boxall EH. Assessing the infectivity of hepatitis carriers. Commun Dis Public Health 1999;2:178-83.

39. Chamberland ME, Petersen LR, Munn VP. Human immunodeficiency virus infection among health care workers who donate blood. Ann Intern Med 1994;121:269-73.

40. Klein RS, Phelan JA, Freeman K, et al. Low occupational risk of human immunodeficiency virus infection among dental professionals, N Engl J Med 1988;318:86-90.

41. Ciesielski CA, Marianos DW, Schochetman G, Witte JJ, Jaffe HW. The 1990 Florida dental investigation. The press and science. Ann Intern Med 1994;121:886-8.

42. Ou C-Y, Ciesielski CA, Myers G, et al. Molecular epidemiology of HIV transmission in a dental practice. Science 1992;256;1165-71.

43. Danila RN, MacDonald KL, Rhame FS, et al. A look-back investigation of patients of an HIV-infected physician. N Engl J Med 1991;325:1406-11.

44. Jaffe HW, McCurdy JM, Kailsh ML, et al. Lack of transmission in the practice of a dentist with AIDS. Ann Intern Med 1994;121:855-9.

45. Mishu B, Schaffner W, Horan JM, Wood LH, Hutcheson RH, McNabb PC. A surgeon with AIDS. Lack of evidence of transmission to patients. JAMA 1990;264:467-70.

46. Longfield JN, Brundage J, Badger G, et al. Look-back investigation after human immunodeficiency virus seroconversion in a pediatric dentist. J Infect Dis 1994;169:1-8.

47. Donnelly M, Duckworth G, Nelson S, et al. Are HIV lookbacks worthwhile? Outcome of an exercise to notify patients treated by an HIV infected health care worker. Commun Dis Public Health 1999;2:126-9.

48. Robert LM. Chamberland ME, Cleveland JL, et al. Investigations of patients of health care workers infected with HIV. The Centers for Disease Control and Prevention Database. Ann Intern Med 1995;122:653-7.

49. Lot F, Séguier J-C, Fégueux S, et al. Probable transmission of HIV from an oprthopedic surgeon to a patient in France. Ann Intern Med 1999;130:1-6.

50. Gerberding JL. Provider-to-patient HIV transmission: How to keep it exceedingly rare. Ann Intern Med 1999;130:64-5.

51. Cooper BW, Krusell A, Tilton RC, Goodwin R, Levitz RE. Seroprevalence of antibodies to hepatitis $\mathrm{C}$ virus in high-risk hospital personnel. Infect Control Hosp Epidemiol 1992;13:82-5.

52. Klein RS, Freeman K, Taylor PE, Stevens CE. Occupational risk for hepatitis $\mathrm{C}$ virus infection among New York dentists. Lancet $1991 ; 338: 1539-42$

53. Thomas DL, Grununger SE, Siew C, Joy ED, Quinn TC. Occupational risk of hepatitis $\mathrm{C}$ infections among general dentists and oral surgeons in North America. Am J Med 1996;100:41-5.

54. Duckworth GJ, Heptonstall J, Aitken C, Incident Control Team and Others. Transmission of hepatitis $\mathrm{C}$ virus from a surgeon to a patient. Commun Dis Public Health 1999;2:188-92.

55. CDSC. Transmission of hepatitis $C$ virus from surgeon to patient prompts lookback. Commun Dis Rep CDR Wkly 1999;9:387.

56. Ross RS, Viazov S, Thormählen M, et al. Risk of hepatitis C virus transmission from an infected gynecologist to patients. Arch Intern Med 2002;162:805-10.

57. Ross RS, Viazov S, Gross T, Hofmann F, Seipp H-M, Roggendorf M. Transmission of hepatitis $\mathrm{C}$ virus from a patient to an anesthesiology assistant to five patients. N Engl J Med 2000;343:1851-4.

58. CDC. Recommendations for prevention and control of hepatitis $C$ virus (HCV) infection and HCV-related chronic disease. MMWR 1998;47(RR-19):1-39.

59. National Health Service. Hepatitis B infected health care workers. $<$ http://www.doh.gov.uk/agh/020hsc.pdf> (Version current at July 15, 2003).

60. Department of Health. Hepatitis C infected health care workers. <http://www.doh.gov.uk/hepatitisC/hepcguidancehcw.pdf $>$ (Version current at July 15, 2003).

61. Department of Health. HIV infected health care workers: A consultation paper on management and patient notification. <http://www.doh.gov.uk/pub/docs/doh/aids.pdf> (Version current at July 15,2003 ) 


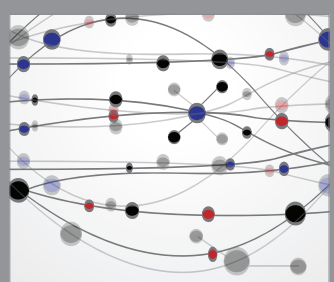

The Scientific World Journal
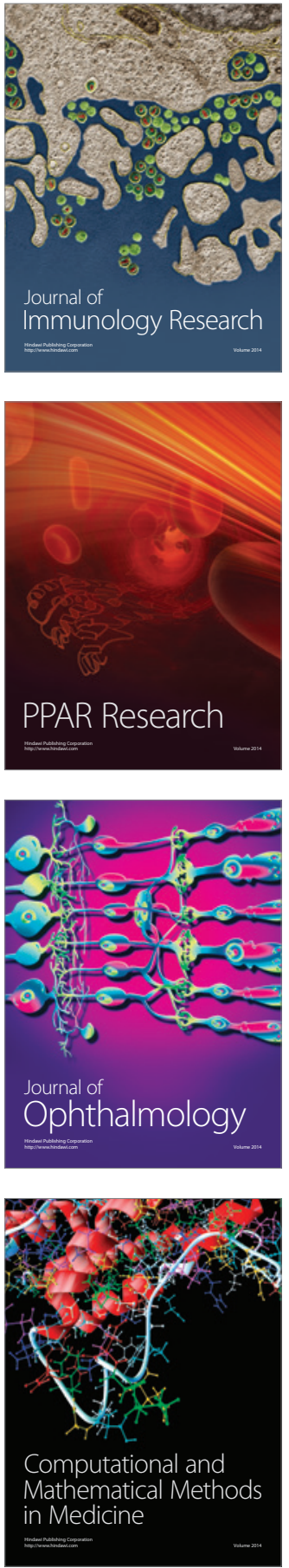

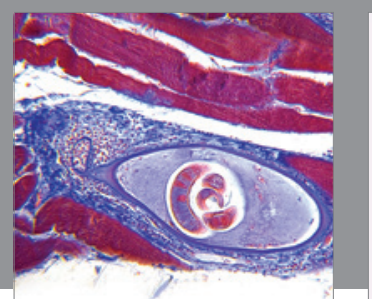

Gastroenterology Research and Practice

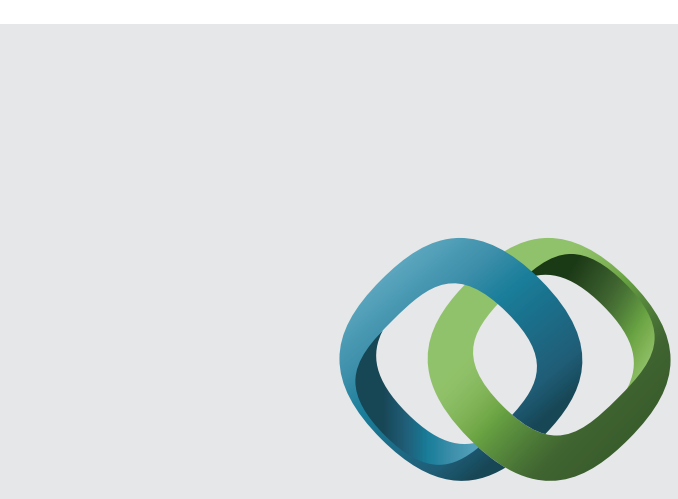

\section{Hindawi}

Submit your manuscripts at

http://www.hindawi.com
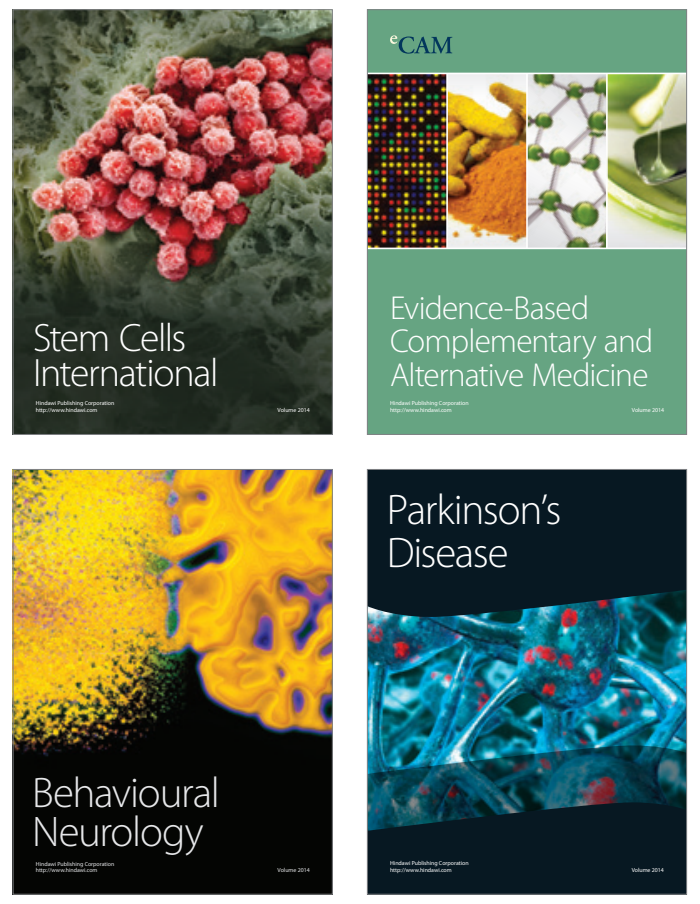
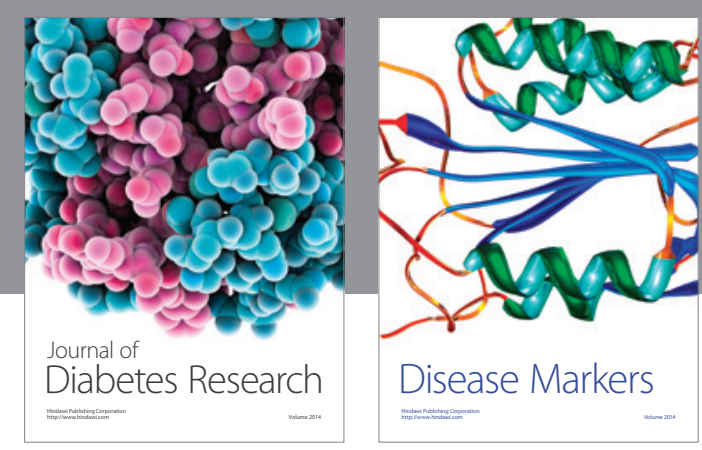

Disease Markers
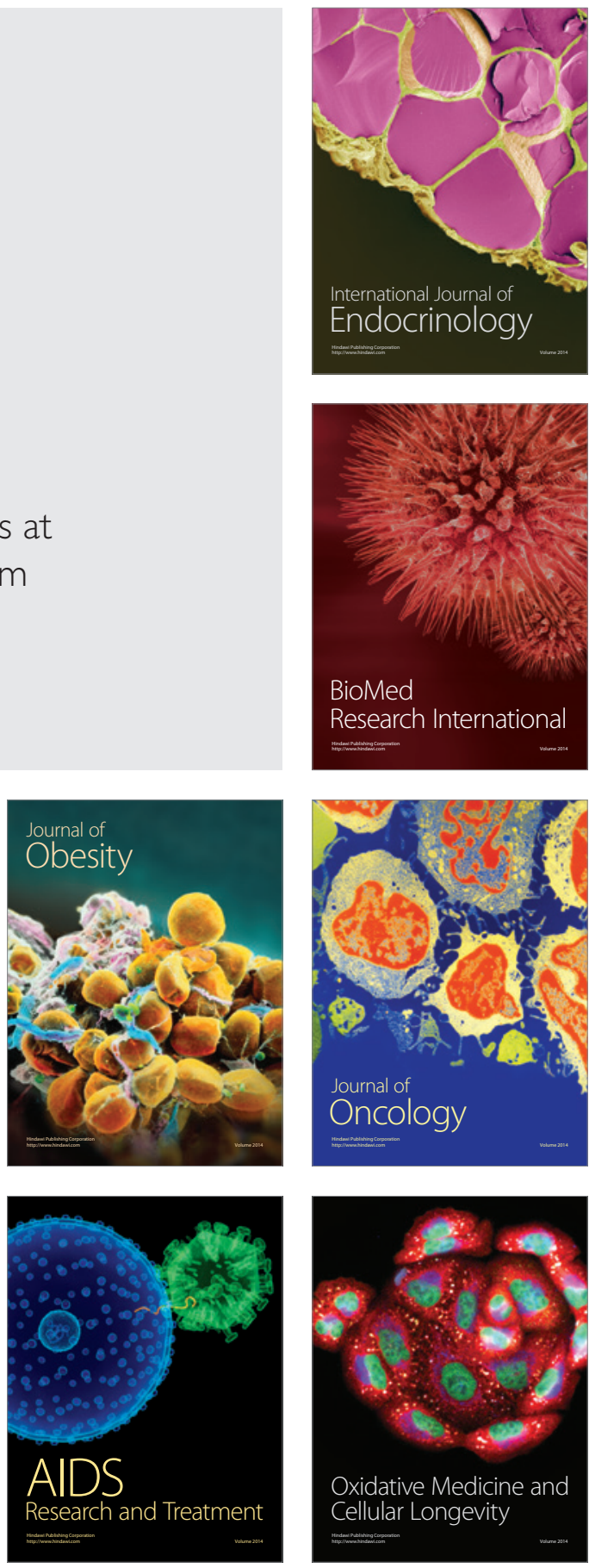